Chapter 4

\title{
Five Things You Didn't Want to Know about Hydraulic Fractures
}

Vincent M. C.

Additional information is available at the end of the chapter

http://dx.doi.org/10.5772/56066

\begin{abstract}
It is common to envision and design hydraulic fractures as if they were simple, planar features that are relatively consistent in width and durable in their flow capacity. Production forecasting is frequently based on a simplified description of the reservoir as a homogeneous single productive layer. In rare instances the pay intervals may be simulated with as many as a dozen layered strata, but even the most meticulous reservoir engineer may mistakenly assign each layer a highly conductive, durable connection with the wellbore. When analyzing the resulting production data, similar assumptions are made, which can erroneously reinforce these misconceptions.

Although our industry has been confronted with photographic evidence from minebacks and core-throughs of actual fractures, we have typically failed to incorporate those complexities and challenges into our design, interpretation, and optimization processes. Similarly, we frequently fail to recognize the challenges of highly laminated and highly compartmentalized reservoirs. In many resource plays, hydraulically stimulated horizontal wells appear to be the only completion technique that can achieve economic production rates from these low permeability reservoirs. However the productivity and ultimate recovery from these horizontal wells will be increasingly reliant on durable hydraulic fractures to contact and drain the hydrocarbons through highly laminated formations for the decades necessary to deplete low permeability reservoirs. Oversimplified models typically result in poorly designed completions and missed opportunities. Frequently, the underperformance of a well will be blamed on "poor reservoir quality" instead of correctly recognizing the inadequacy of our created fractures.
\end{abstract}


This paper will examine five limitations of hydraulic fractures and interpretation techniques, and describe the increases in well productivity that can be achieved when efforts are made to address and compensate for these deficiencies.

Keywords Frac optimization, resolving non-unique solutions, proppant degradation, realistic conductivity, laminated reservoirs, complexity, restimulation

\section{Introduction}

Early frac engineers certainly recognized that hydraulic fractures were complex features. Geologists, mining engineers, and prison chain gangs all assured us that rocks break in complex manners. But the math is hard, and we aren't capable of predicting nature's complexity. We cannot accurately calculate the pressure losses through a proppant pack with complex geometry, irregular aperture, and with several fluid phases flowing at high velocity. So our predecessors were forced to simplify the description. As a first-order approximation, they assumed that fracs were simple, vertical planes, with uniform width and predictable hydraulic continuity.

Two subsequent generations of petroleum engineers have been introduced to simplified planar hydraulic fractures that have been distorted to fit on a textbook page, such as in Figure 1. Unfortunately, many engineers mistakenly envision fracs as wide, highly conductive channels instead of thin, narrow ribbons of proppant that extend deeply into the reservoir but are vulnerable in their hydraulic continuity. Fractures are commonly modeled to be symmetrical, bi-wing planes that reliably contact the targeted hydrocarbons.
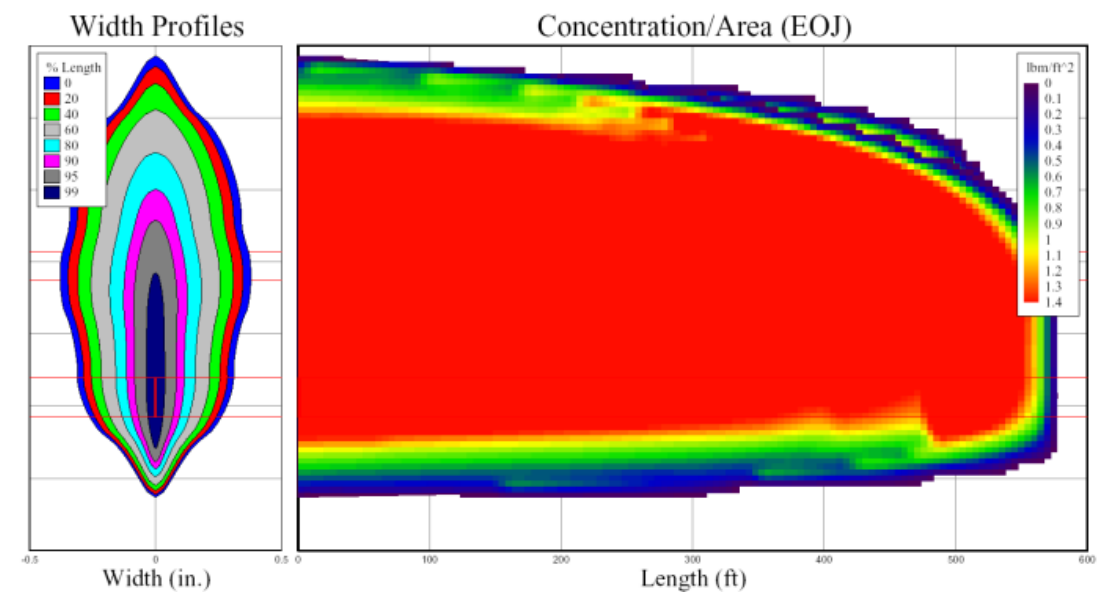

Figure 1. The proportions of fractures are often distorted and misrepresented in simplified models. This figure implicitly assumes the fracture grows symmetrically on either side of the wellbore. 
Although chemical engineers clearly recognized that Darcy's flow would not describe pressure losses in porous media, early frac engineers disregarded non-Darcy and multiphase flow effects, and further assumed a single homogeneous reservoir layer was contacted by a highly conductive fracture that permanently connected the wellbore to the hydrocarbons. These assumptions allowed the "optimization" of frac treatments to become a mathematically simple routine. Two subsequent generations of petroleum engineers have filled our literature and conventional wisdom with simulations and "rules of thumb" that would allow us to optimize these mythical ideal fractures. Unfortunately, many of the assumptions are wrong, and our fracs are not optimized.

\section{Complex flow regimes}

Even if fractures were simple, wide features, with perfectly uniform proppant arrangements throughout the entirety of the fracture length and height, our industry would still overestimate the flow capacity of fractures by several orders of magnitude. Figure 2 shows the apparent flow capacity of proppant packs, measured in the laboratory.

\section{Realistic Conductivity Reductions}

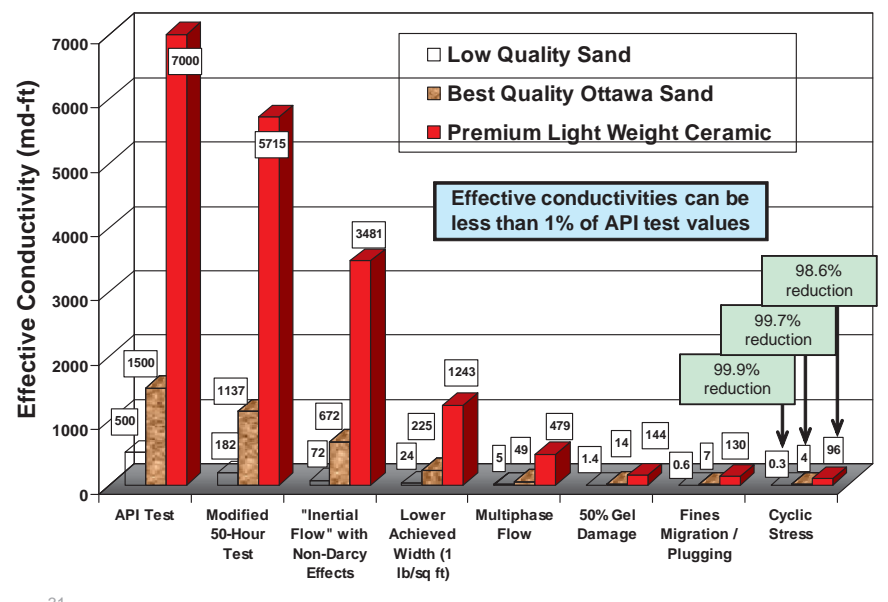

Figure 2. Even in simple, planar proppant packs with uniform proppant distribution, the effective conductivity is frequently 50 to 1000 times lower than published values [1]

Conductivity data provided by most proppant vendors, and utilized in most production simulators are collected with test procedures similar to the left two categories of bar columns in Figure 2. When testing is more sophisticated, with realistic velocities of multiphase fluids through proppant packs subjected to gel damage and cyclic stress oscillations, the pres- 
sure losses are often found to be orders of magnitude higher than indicated by reference data $[1,2,3]$.

\section{Conductivity degrades}

Even the meager amount of effective conductivity shown in Figure 2 appears to be unsustainable. Five different researchers have published the performance of proppants when tested in the laboratory for weeks instead of hours Montgomery [4], McDaniel [5], Cobb [6], Hahn [7], Handren [8]. All five have shown that proppants lose conductivity over time, with one representative test shown in Figure 3. Some proppants are more durable than others, and some laboratory conditions will more rapidly degrade proppant, but not a single proppant pack in the lab has sustained flow capacity without continued particle breakage and compaction during extended testing. The degradation mechanism in these tests has nothing to do with chemical damage, scale deposition, or diagenesis - these conductivity losses are related to the strength of the particles, and show similar trends when tested in dry nitrogen gas, in oil, or in brine, when confined between sandstone, stainless steel, or Teflon. [5, 9, 10]. It is surprising that none of our models incorporate frac degradation over time, despite unanimous evidence that conductivity declines.

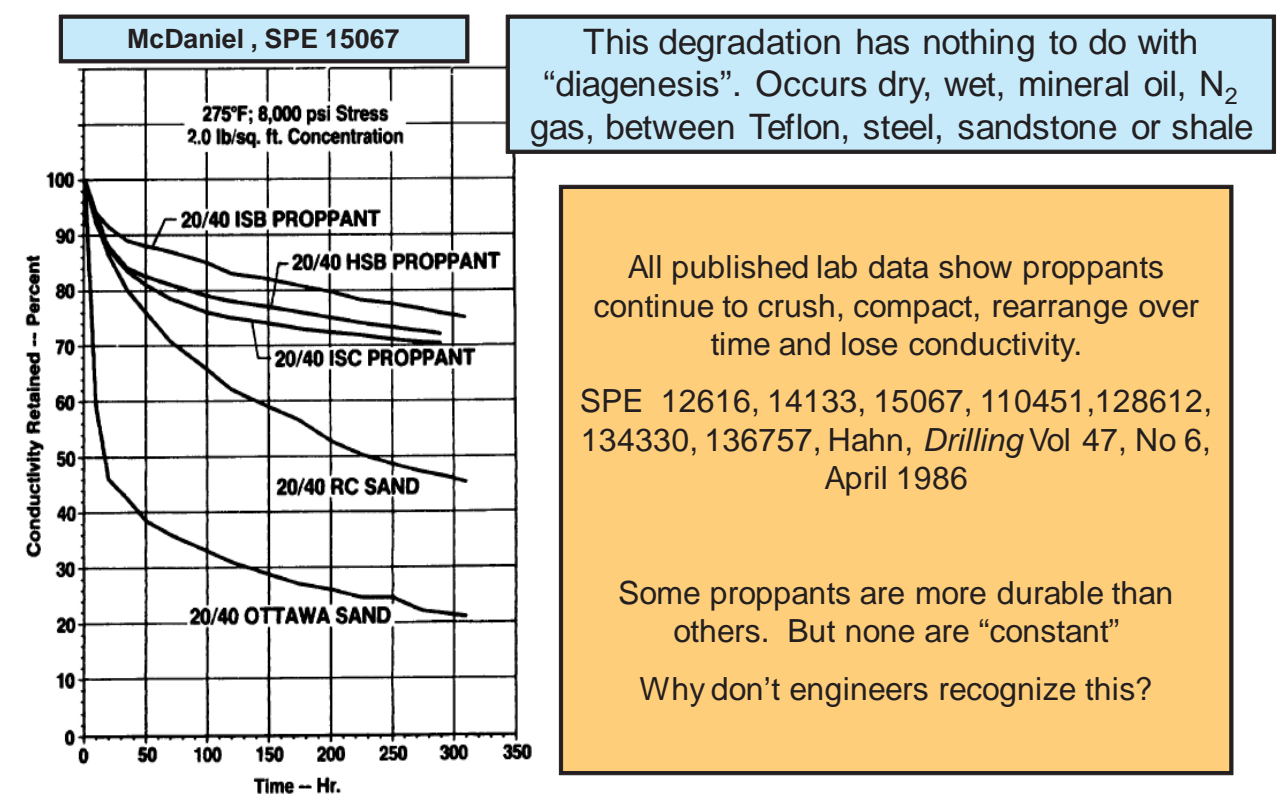

Figure 3. Extended duration tests routinely show continued mechanical crush and loss of flow capacity of proppant packs [5] 


\section{Heterogeneous reservoirs}

Production forecasting is greatly simplified if the reservoir can be described as a uniform layer with predictable, consistent permeability in the vertical and horizontal directions. However, sedimentary rocks were formed from hundreds or thousands of sequential layers of sediment as shown in Figure 4. Productive lenses can have varying lateral extent.
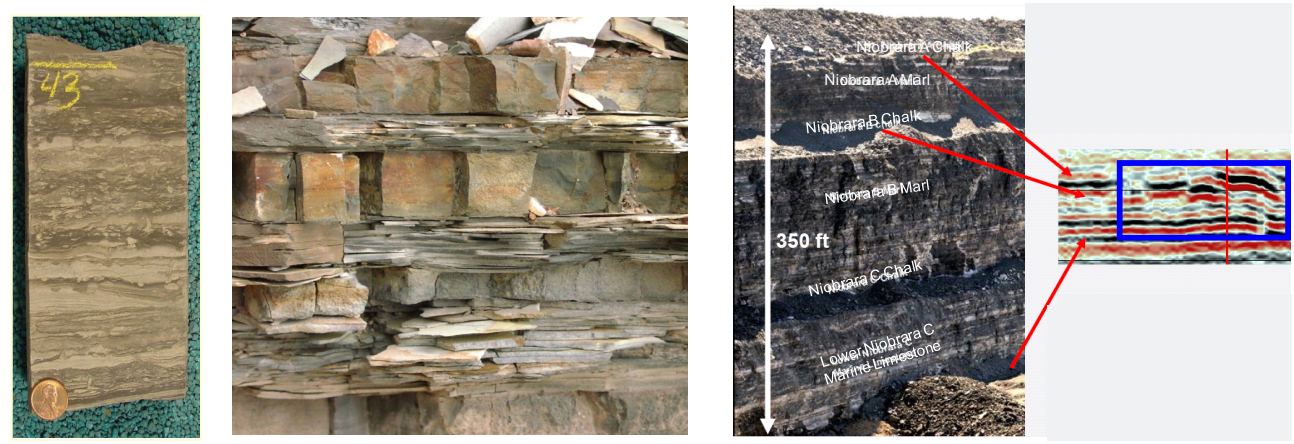

Figure 4. On every scale, formations may have laminations that hinder vertical permeability and fracture penetration. Shown are thin laminations in the Middle Bakken [11], layering in the Woodford [outcrop photo courtesy of Halliburton], and large scale laminations in the Niobrara [adapted from 12] [13]

The consequences of these laminations are two-fold:

1. Vertical perm is terrible. Often the vertical perm is only a tiny fraction of the horizontal perm; $\mathrm{k}_{\mathrm{v}} / \mathrm{k}_{\mathrm{h}}<0.001$. Oil and gas do not move easily in the vertical direction through rock. If you want to drain it, you have to frac it. Especially with horizontal wells drilled into a single layer, the frac engineer must create a durable, conductive pathway breaching the laminations within the hydrocarbon-bearing intervals if we have a prayer of draining the reserves from these tight, laminated resource plays, unless pre-existing natural fractures provide a vertical flow path.

2. Laminations hinder frac penetration [13]. Fracs don't like to grow through a series of bonded and unbonded layers (Fig 5).

\section{Complex frac geometry}

Figure 5 depicts conceptualized fracture branching as it grows through a laminated formation. Figure 6 shows minebacks of actual fracturing treatments performed at the Nevada test site and Figure 7 shows a core-through of a treatment in the Piceance Basin of western Colorado. 


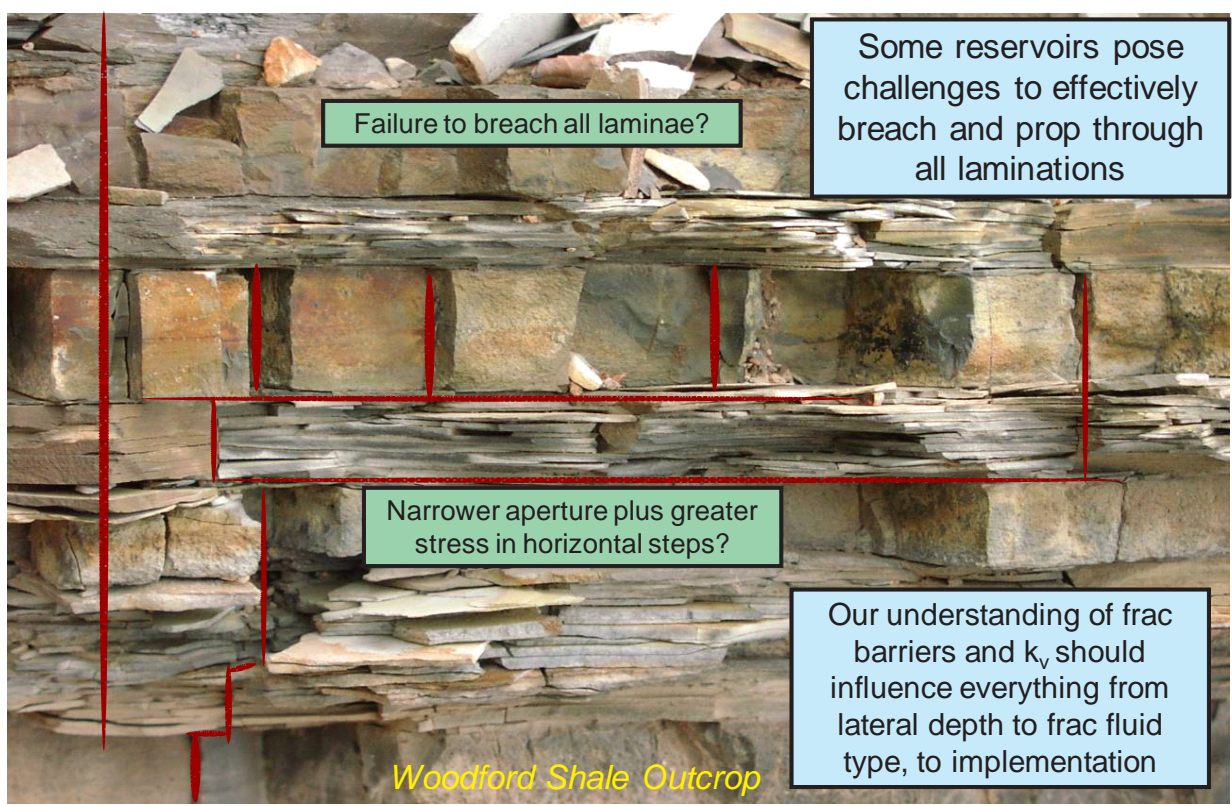

Figure 5. Instead of perfectly vertical fractures (left) it may be appropriate to anticipate difficulty creating and sustaining a conductive fracture throughout the entire pay interval [outcrop photo courtesy of Halliburton [13].
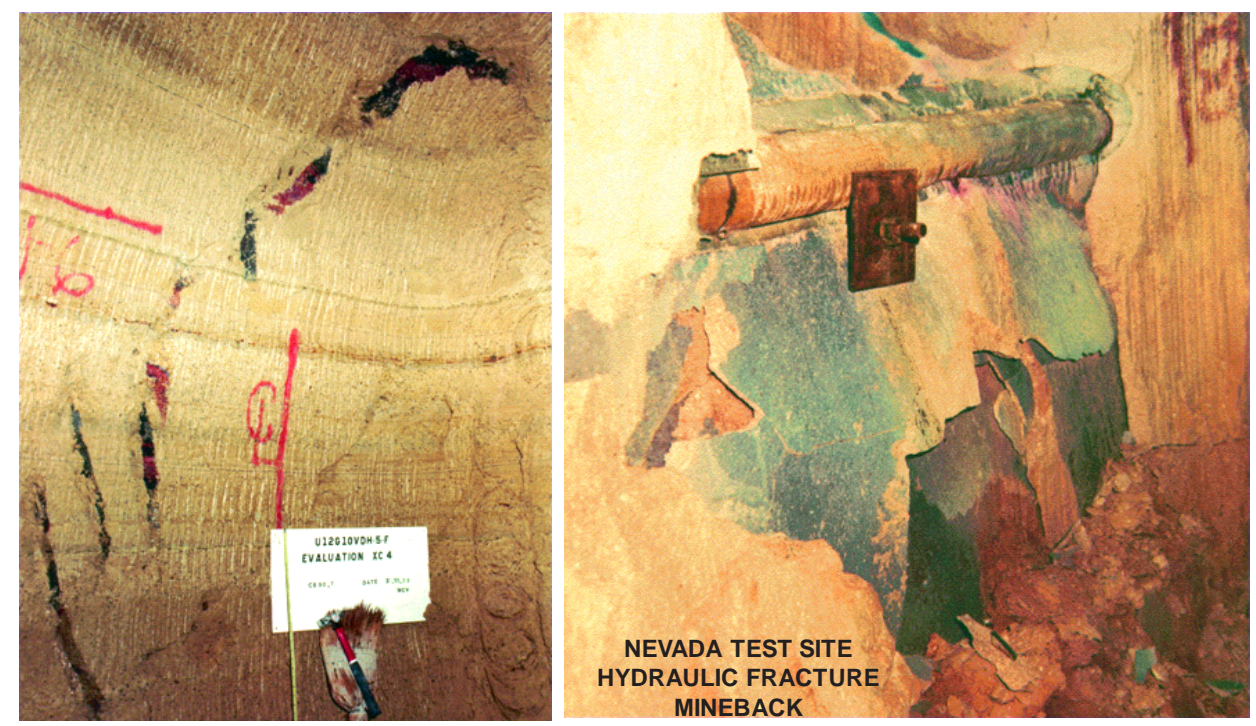

Figure 6. Photographs of mine backs at the Nevada test site demonstrate complexity $[1,14,15]$ 


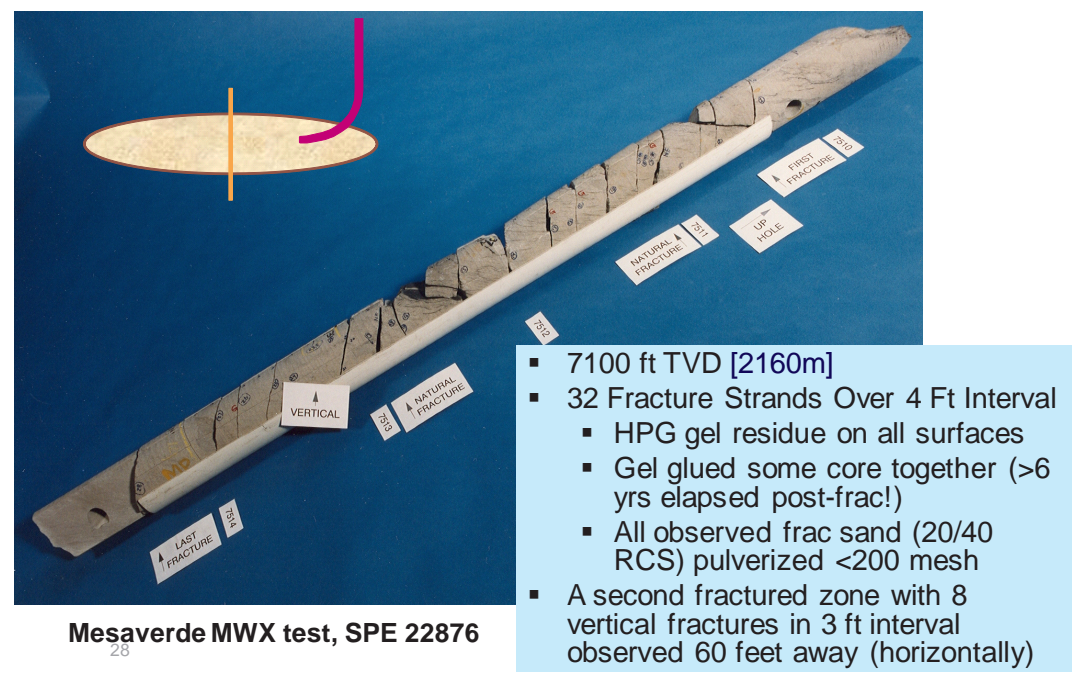

Figure 7. In the Piceance Basin, cores through a created fracture document 40 fracture strands, with only pulverized resin coated sand recovered $[1,16]$

Clearly, there is evidence that fractures can grow in much more complicated manners compared to the simple, planar features that are typically presumed in our designs and "optimization" attempts. What are the implications of complexity shown in Figure 8?

\section{Is Fracture Complexity Good or Bad?}

\section{Simple Fracture}

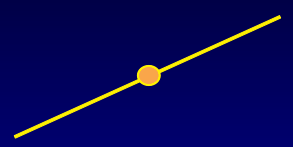

Complex Fracture

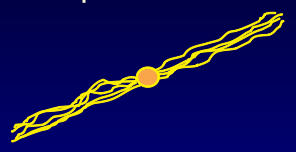

Very Complex Fracture Network

Pro:

Complex fracs increase

the reservoir contact (beneficial in nanoDarcy shales?)

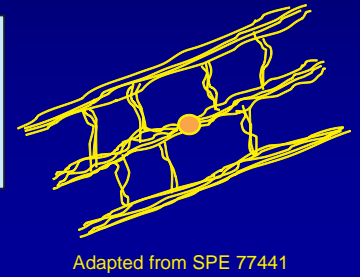

\section{Con:}

Complex fracs complicate the flow path, and provide less cumulative conductivity than simple, wider fractures [SPE 115769]

Figure 8. Fracture complexity increases reservoir contact, but challenges our ability to create a durable proppant pack with sufficient hydraulic continuity [adapted from 17] 
Hydraulic fractures must achieve two primary objectives. They must:

1. Touch rock (contact hydrocarbons)

2. Provide a durable conduit for hydrocarbons to flow to the well with acceptable pressure losses (sufficient conductivity)

Complex, branching fractures do an excellent job of touching rock. However, they challenge our ability to place a commensurate degree of conductivity. Branching, complex features are often ineffectively propped, with risk of insufficient conductivity and continuity.

\section{Non-unique interpretations}

The fifth thing we don't want to know about fractures is that it is nearly impossible to identify the deficiencies when analyzing production data from a single well. Figure 9 shows the production history (decline curve and cumulative production) from a single fractured interval, along with three plausible production matches.
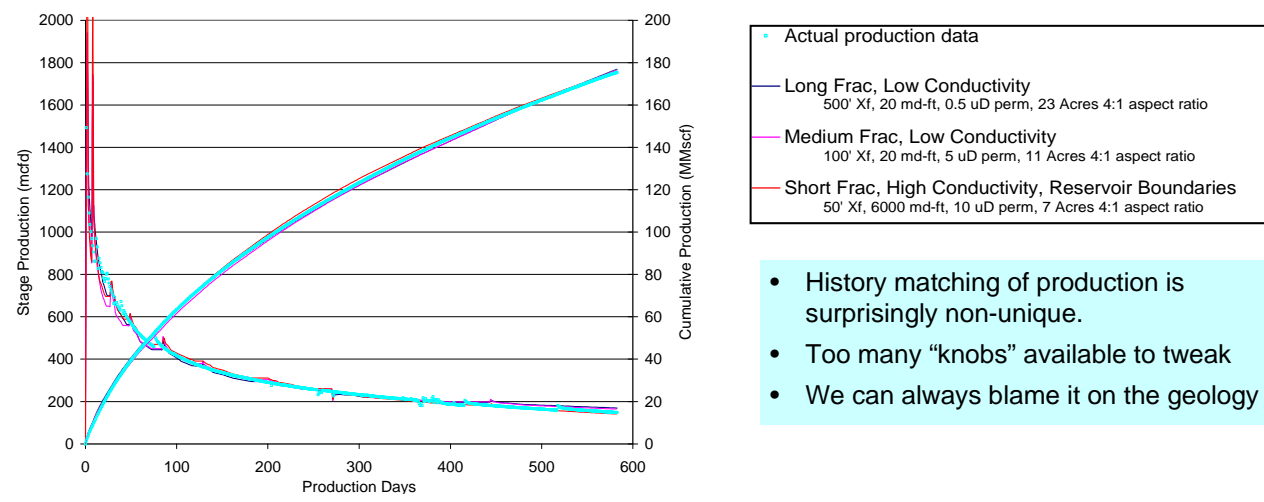

Figure 9. With a single well, the production history can be matched with a nearly infinite combination of plausible fracture and reservoir descriptions $[18,19]$

From a single decline curve, we cannot uniquely determine whether the fracture is short and "infinitely conductive," or long with more significant pressure losses. We cannot prove from a decline curve whether the fracture was simple or complex in geometry. We cannot prove whether the fracture conductivity was constant or degrading. Most engineers attempt to match the data with an analytic solution or a numerical simulator that presumes the frac is fully packed with proppant throughout, providing uniform and durable flow capacity without collapse of poorly propped sections. Note that with this approach an engineer can continue to reinforce any existing misconceptions. Fracs can be interpreted to be long or short. Disap- 
pointing well productivity can always be blamed on the geology - with no irrefutable proof that the fracture was insufficient.

\section{Discussion of five deficiencies}

There are certainly more than five deficiencies in our stimulation designs and our techniques to analyze well production. However, the five issues described in this paper include:

1. Hydrocarbons move in a complex manner within propped fractures, increasing the pressure losses by 50 to 1000 -fold over common expectations, even if the fractures are planar and fully propped.

2. Fracture conductivity is not constant. Lab data suggest that all conventional proppant types suffer continued crush and compaction over time.

3. Reservoirs are laminated and compartmentalized. Especially with horizontal drilling, ultimate recovery is far more dependent on fracture continuity through laminations than in vertical wells in which each prospective layer can be perforated and individually stimulated. With low perm reservoirs, significantly longer well life (and proppant durability) will be required to drain the available reserves.

4. Fractures develop varying degrees of complexity. This is both good and bad. Reservoir contact is increased as fractures branch, twist, and energize pre-existing planes of weakness. However, this complexity challenges our ability to place a durable, hydraulically continuous proppant pack with conductivity commensurate to carry hydrocarbons with an acceptably small pressure loss.

5. History-matching of production data is surprisingly non-unique. An engineer can reinforce misconceptions throughout an entire career without encountering any results that cannot be matched with a simple, planar frac of durable, high conductivity in a homogenous reservoir. Underperformance can always be attributed to other factors.

While this is a fairly depressing view of the problem, there are techniques to remove some of the uncertainty and ambiguity allowing significant improvement in the performance of stimulation treatments.

\section{Removing the uncertainty}

Several datasets and techniques can be used to more uniquely describe the performance of propped fractures [19]:

- Wells that are restimulated. When we refrac a well, we have an opportunity to history-match the production from the initial and subsequent stimulation treatments using only a single reservoir description. Difference in well production must be uniquely attributed to the frac 
design. There have been more than 140 published examples, and history-matching attempts have frequently indicated that fractures are not as effective or durable as previously anticipated [10, 20].

- Fields in which a carefully conducted field trial examines the role of a single variable in fracture design. For instance, when 150 wells are treated at 4 ppg and 150 offset wells are systematically selected to receive 6 ppg slurry, it is possible to achieve comparisons with compelling statistical significance. The difference in productivity is known to relate to the frac performance, and cannot be attributed to reservoir parameters. The evaluation of 200 published field examples [1] provides very credible evidence that fracs do not perform as most people anticipate, and that increased focus on fracture conductivity is merited.

- Wells that are connected by a propped fracture. As described previously, fractures can reach impressive lateral dimensions. It is not uncommon for fractures to intersect adjacent wellbores completed at the exact same depth or in the same formation subinterval. When this occurs, it provides a significant opportunity to investigate the initial and sustained continuity over time. In most cases, adjacent wells appear to lose hydraulic continuity over time, suggesting that the connecting fracture "collapses" or "heals".

- Infill drilling. In many tight reservoirs, we have successfully drilled wells within 200 feet of existing wells and encountered near-virgin reservoir pressures. In many shale reservoirs, infill wells are anticipated to recover nearly $80 \%$ of the reserves of adjacent parent wells drilled many years earlier, demonstrating that initial wells have not captured the available reserves.

- More sophisticated modeling and data analyses. While simple production data analyses yield non-unique solutions, several degrees of freedom can be removed with careful analyses of pressure-transient or rate-transient data. There have also been advances in interpretation of flow regimes from wells with complicated fracture networks. Even in the 400-nanoDarcy Barnett shale, production data do not indicate that the entire created network remains highly effective.

These efforts strongly indicate that additional focus on the conductivity, durability and effectiveness of the fracture is needed - not just a focus on created dimensions.

\section{Opportunities to improve fracture performance}

It is important to recognize that our intuition, our models, and our traditional interpretations of fracture performance are flawed, and can prevent us from recognizing opportunities to improve well productivity. While our industry has collected data demonstrating complexities (in reservoir description, in fluid flow regimes, in fracture geometry, in durability of proppant packs), the industry has been very slow to adapt designs to accommodate or capitalize on these realities.

More than a dozen specific recommendations have previously been discussed [19] to improve the productivity and profitability of fracturing treatments. However, a general theme is to 
continue experimenting and studying production from wells, with a healthy skepticism of model predictions and of historic rules of thumb regarding fracture design. Another common finding is that emphasis on improving the effectiveness and durability of treatments appears to be adding more value than blindly focusing on fracture length or treatment volume. There are a great number of field examples in which modest changes to fracturing designs resulted in very large changes to well productivity, convincingly demonstrating that our initial frac designs were insufficient to capture the full well potential. Figure 10 shows surprising increases in productivity were achieved by restimulating a modest perm oil reservoir and a tight gas reservoir with improved fracture designs more focused on the durability and conductivity of the fracturing treatments.
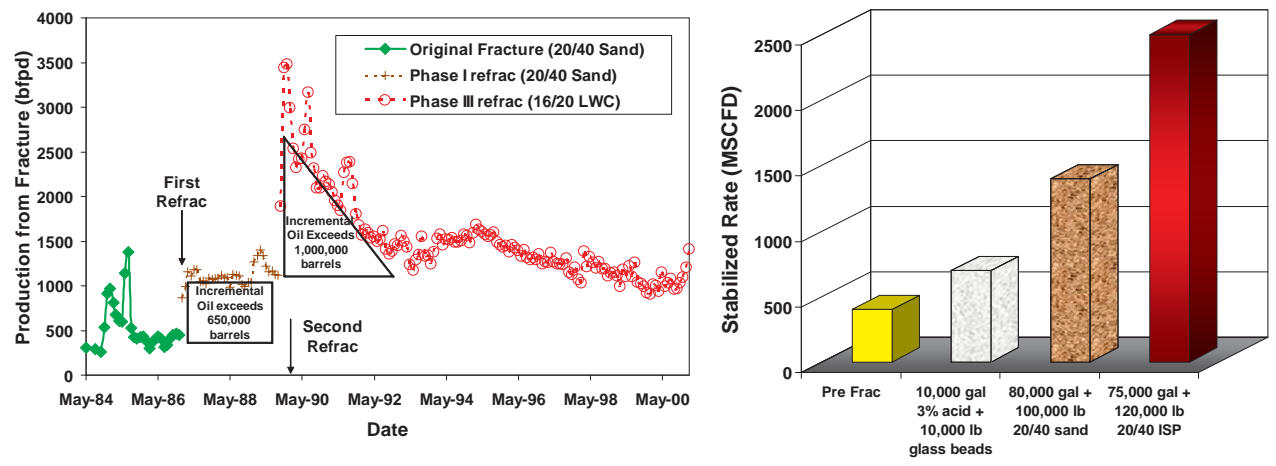

Figure 10. Experimentation with frac design often demonstrates the well potential is constrained by insufficient fracture designs $[1,20]$

Similar production increases have been documented in hundreds of field studies in shales, carbonates, coals, and sandstones [1]. On one hand, it is frustrating to admit that after decades we have failed to optimize our fracturing treatments. On the other hand, it is great news that our fracs are not optimized. Reservoirs are often capable of tremendous increases in productivity with improved fracture designs that accommodate and capitalize on our understanding of complexity.

\section{Author details}

Vincent M. C.*

Address all correspondence to: mike@fracwell.com

Fracwell Llc, Golden, Colorado, USA 


\section{References}

[1] Vincent, M. C. (2009). Examining our Assumptions- Have Oversimplifications Jeopardized Our Ability to Design Optimal Fracture Treatments? Paper SPE 119143 presented at the 2009 Hydraulic Fracturing Technology Conference, The Woodlands, Jan , 19-21.

[2] Barree, R. D, Cox, S. A, Barree, V. L, \& Conway, M. W. (2003). Realistic Assessment of Proppant Pack Conductivity for Material Selection. SPE paper 84306 presented at the Annual Technical Conference, October , 5-8.

[3] Palisch, T, Duenckel, R, Bazan, L, Heidt, H. J, \& Turk, G. (2007). Determining Realistic Fracture Conductivity and Understanding its Impact on Well Performance- Theory and Field Examples. SPE paper 106301 presented at the 2007 Hydraulic Fracturing Technology Conference, College Station, TX, Jan , 29-31.

[4] Montgomery, C. T, \& Steanson, R. E. (1984). Proppant Selection- The Key to Successful Fracture Stimulation. SPE paper 12616 presented at the Deep Drilling and Production Symposium, Amarillo, TX April , 1-3.

[5] Mcdaniel, B. W. (1986). Conductivity Testing of Proppants at High Temperature and Stress. SPE Paper 15067 presented at the 56th California Regional Meeting, Oakland, April , 2-4.

[6] Cobb, S. L, \& Farrell, J. J. (1986). Evaluation of Long-Term Proppant Stability. SPE paper 14133 presented at the International Meeting on Petroleum Engineering, Beijing, Mar, 17-20.

[7] Hahn, G. (1986). How Long will it Prop? Drilling, the Wellsite Publication. Issue 596, April 1986., 47(6)

[8] Handren, P, \& Palisch, T. (2007). Successful Hybrid Slickwater Fracture Design Evolution. Paper 110451 presented at the 2007 Annual Technical Conference, Anaheim, Nov , 11-14.

[9] Duenckel, R, Conway, M. W, Eldred, B, \& Vincent, M. C. (2011). Proppant Diagenesis-Integrated Analyses Provide New Insights into Origin, Occurrence, and Implications for Proppant Performance. SPE paper 139875 presented at the SPE Hydraulic Fracturing Technology Conference, The Woodlands, TX Jan , 24-26.

[10] Vincent, M. C. Do They Work, and Why Do They Fail in 100 Published Field Studies?, SPE 134330 presented at the 2010 Annual Technical Conference, Florence, Italy, Sept, 19-22.

[11] LeFeverJ. (2005). Overview of Bakken Stratigraphy and "Mini" Core Workshop. AAPG Rocky Mountain Meeting Short Course \#1, Jackson, WY, Sept 24.

[12] Noble Energy Analyst Conference(2010). June 3. 
[13] Vincent, M. C. (2011). Optimizing Transverse Fractures in Liquid-Rich Formations, SPE 146376 presented at the Annual Technical Conference, Denver, CO Oct Nov 2., 30.

[14] Warpinski, N. R. (1983). Investigation of the Accuracy and Reliability of In Situ Stress Measurements Using Hydraulic Fracturing in Perforated, Cased Holes. Proceedings, 24th U.S. Symposium on Rock Mechanics, Texas A\&M University, College Station, TX, June 20-22, 1983., 773-786.

[15] Warpinski, N. R, Tyler, L. D, Vollendorf, W. C, \& Northrop, D. A. Direct Observation of a Sand-Propped Hydraulic Fracture," Sandia National Laboratories Report, SANDMay (1981). , 81-0225.

[16] Warpinski, N. R, et al. (1993). Examination of a Cored Hydraulic Fracture in a Deep Gas Well. SPE 22876, SPEPF Aug , 1993, 150-158.

[17] Fisher, M. K, et al. (2002). Integrating Fracture Mapping Technologies to Optimize Stimulations. Paper SPE 77441 presented at the SPE Annual Technical Conference, San Antonio, Sep. Oct. 2., 29.

[18] Vincent, M. C, et al. (2007). Field Trial Design and Analyses of Production Data from a Tight Gas Reservoir: Detailed Production Comparisons form the Pinedale Anticline. SPE paper 106151 presented at the 2007 Hydraulic Fracturing Technology Conference, College Station, TX Jan , 29-31.

[19] Vincent, M. C. (2012). The Next Opportunity to Improve Hydraulic-Fracture Stimulation. JPT Distinguished Author Series, March SPE 144702., 2012-118.

[20] Vincent, M. C. (2010). Restimulation of Unconventional Reservoirs: When are Refracs Beneficial?. JCPT June 2011, SPE 136757 presented at the Canadian Unconventional Resources \& International Petroleum Conference, Calgary, Oct. , 19-21. 
